\title{
On Wu Jingzi's Ideological Tendency from the Shaping of Dushaoqing Wang Yan ${ }^{1, a}$
}

\author{
China; Zhejiang; 9 Xuefu Road, Yinzhou District, Ningbo (Ningbo College of Vocational \\ Technology)
}

Keywords: Du Shaoqing; Confucian gene; the fashion of Wei and Jin Dynasties; Zeitgeist; Wu Jingzi

\begin{abstract}
The novel of Unofficial History about Scholars as a class is one milestone of Ancient Chinese vernacular satirical novels. Du Shaoqing,the orthodox Confucianism ,the fashion of Wei and Jin Dynasties,and the Advanced and Ideological Trend of the Ming and Qing Dynasties. There-fore, the analysis of the Image of Du Shaoqing, undoubtedly, is of great significance to comprehend the ideological tendency of Wu Jingzi, even the social reality and political environment.As a master of the Realism, Wu Jingzi's thoughts is more advanced than the previous and many other contemporary writers, however,because of certain restrictions of historical conditions and his own factors, there are some limitations in Wu Jingzi's thought.
\end{abstract}

\section{从杜少卿形象塑造看吴敬梓的思想倾向 \\ 王 岩 \\ 1宁波城市职业技术学院，鄞州，宁波，浙江，中国}

关键词：杜少卿；儒家基因；魏晋风尚；时代精神；吴敬梓

中文摘要：《儒林外史》中的杜少卿是科举世家的叛逆者, 是魏晋风尚的践行者, 也是儒家思 想的守望者。从他的身上能折射出作者的思想结构：正统儒家思想的支配、魏晋六朝风尚的 熏染、明清之际先进思潮的影响。因此, 分析杜少卿的形象塑造, 对解读吴敬梓的思想倾向, 乃至当时的社会现实、政治环境有着重大意义。作为现实主义大师的吴敬梓，其思想高度超 出了前代和同时代的许多作家，但由于时代条件和自身因素的某些限制，还是表现出一定的 局限性。

\section{1.引言}

《儒林外史》堪称中国古代白话讽刺小说的一座里程碑，吴敬梓通过塑造形象生动的人 物、鲜明巧妙的对比, 给读者展示了一幅活灵活现的明末儒林现形图。这里有精神空虚、道 德沦丧、昏庸腐败、欺压良民的“衣冠离兽”; 有自命风雅、沽名钓誉、虚伪无聊、孤芳自赏 的“斗方名士”; 有尚礼尊贤、安贫乐道、淡泊名利、超凡脱俗的真儒名士; 有狂放不羁、纯 任自然、自由豪放、傲视权贵的市井奇人。在这形形色色的人物中，绽放着一朵儒林奇菂一 杜少卿。他是狂生, 充斥着离经叛道的色彩; 他亦是儒士, 始终无法完全打破儒家思想的藩 篱; 他深受魏晋六朝风尚的熏染; 他的身上还有明清之际先进思潮打下的时代烙印。他的形 象立体丰满，有着丰富复杂的性格特征和思想内涵。剖析“乃作者自况”[1]的杜少卿，对更深 入地解读吴敬梓的思想倾向，更全面地认识当时的现实社会和政治环境有着重大意义。 


\section{2. 杜少卿人物形象的塑造}

《儒林外史》是一部取材于现实社会的小说，吴敬梓通过自己的亲身经历，以及对现实 社会的细致观察和对世态人情的切身体会, 绘成了这一幅活灵活现的明末儒林画卷。小说中 刻画的人物大多确有其人，设置的情节也多确有其事。学界在杜少卿是作者原型这一点上持 一致观点, 这里不细考。从杜少卿形象塑造的分析中, 能清楚地反射出吴敬梓的思想倾向。 本文先分析杜少卿的人物形象，进而解读吴敬梓的思想倾向。

\section{1杜少卿：科举世家的叛逆者}

《儒林外史》所勾描的社会, 是深受功名富贵和八股科举茶毒的社会。儒林万马齐喑, 知识分子处于麻木不仁的精神状态。在世俗眼中, 为了功名富贵, 可以放弃道德底线, 可以 成痴成狂; 在世人眼中, 只有科举出身才是正途, 也是唯一的出路。杜少卿出生科举世家, 号称“一门三鼎甲，四代六尚书，门生故吏，天下都散满了”[2]。如此显赫的家世背景，如此 深厚的科举底蕴, 家族寄予他的厚望、世俗认定他的正途, 然而他不受世俗观念的侵蚀, 不 走寻常路, 成为科举世家的叛逆者。

卿鄙弃功名, 傲视权贵。《儒林外史》以明朝作为创作背景, 展现当时知识分子的精神面 貌和历史命运。明朝的统治阶级为了加强思想专制, 以功名富贵为诱饵, 利用八股科举来钳 制和禁锢知识分子的思想。作为科举世家后代的杜少卿, 却无心科考, 䒼视八股科举, 弃功 名如粉屣。在明清两代, 功名富贵可以说是文人的试金石。在功名富贵这个放大镜下面, 所 有人都无所遁形, 它烛照文人内心，显其灵魂。杜少卿不为功名所动，依然保持独立人格的 难能可贵。

平居豪举，挥金如土。明朝中后期，在古老的封建中国孕育了资本主义的萌芽。然而， 封建统治阶级在经济政治和文化思想上的高压政策，并没有让资本主义得到应有的发展。相 反, 商品经济的畸形发展催生了一批金钱主义势力。《儒林外史》中对金钱势力的代表一一盐 商的刻画, 正是针对这种极端利已的金钱主义和市侩主义的讽刺批判。与这种金钱主义形成 鲜明的对比，杜少卿挥金如土，对钱财视若无物，在很大程度上打击了金钱势力的猖獗。书 中多处描写杜少卿仗义疏财, 而且一般都是典当物产。杜少卿并不在意这些银两的捐助对象 是贤是否, 也不关心银子的用处, 所以常有狐朋狗党和了奴欺骗他的家财。就像娄老爹临死 前对杜少卿说的一段话: “像你这样做法, 都是被人骗了去, 没人报答你的。虽说施恩不望报, 却也不可这般贤否不分。”在污浊的社会中, 杜少卿用他的挥金如土, 来鄙视金钱势力和市侩 主义的惜金如命，在当时也是一大壮举。

亲近平民，相与甚欢。处在封建末期的明朝，等级制度日益森严，吏治黑暗，地主阶级 与农民阶级及下层人民之间的阶级矛盾愈演愈烈，各地农民起义风起云涌，此起彼伏。统治 阶级用残酷的手段剥削和镇压百姓, 视平民百姓的性命如草芥。出生封建地主阶级家庭的杜 少卿不愿与达官贵人交往, 却喜欢与社会底层的百姓为伍, 赞赏他们自食其力, 向往他们之 间纯朴的人际关系。杜少卿向往的是质朴醇厚的人际关系。他不摆老爷架子，不喜欢别人叫 他老爷, 也不要人向他下趾。他是真心和底层人民交往, 真诚地对待他们, 赞赏他们的才能。

\section{2 杜少卿: 魏晋风尚的践行者}

魏晋风尚“弃经典而尚老庄，若礼法而崇放达”[3]，崇尚淡泊隐逸和超然脱俗，赞赏人的风神 气韵、意态格调, 鄙弃琐事, 讲求真性情, 表现出恣情纵性的特征。杜少卿的身上浸染着浓 厚的魏晋名士色彩，同时又带有一定时代精神的气息。

离经叛道, 茂视权威。汉末社会的巨大动荡动摇了儒学独尊的地位, 到了魏晋时期, 思 想界得到了某种程度的解放。魏晋时代是个“篡夺时代”[4]，但篡权杀人者偏偏要打着礼教的 旗号进行巧取豪夺, 于是阮籍、嵇康等竹林名士“不平之极, 无计可施, 激而变为不谈礼教, 甚至于反对礼教”[5]。随着时代的发展, 魏晋风度逐渐成为后世不愿遵从礼教、循规蹈矩走封 
建正途的文人所追求的一种风范。《儒林外史》中的社会环境虽然是相对安定的明朝, 但是统 治阶级把程朱理学作为正宗文化和官方哲学, 强化三纲五常的礼教色彩, 程朱理学成为统治 知识分子思想的权威, 社会呈现出一派死气沉沉、暗无天日的景象。身处其中的杜少卿对这 样的社会现象极其不满和厌恶。他敢为他人不敢为, 敢于挑战封建权威, 对当时钦定的、朱 喜对经书的注释提出大胆的质疑。当绝大多数人一心投入科举和时文的“大道”时，杜少卿却 纵情于为时人所不齿的诗文“小道”, 还著了一部《诗说》, 表达自己的独特看法, 抗击理学。

率性而为, 纯任自然。这里的“自然”除了是名士们寄情的外在的物化自然外，还是人性 的自然。名士们反对一切违背人之本性的强制, 强调注重本性, 从中可以看出他们对冲破封 建束缚, 追求自由的迫切要求。杜少卿鄙弃功名、遗落物务、追求自在、茞视权威、傲视世 俗、离经叛道, 都体现了他要求个性解放的思想, 他的举手投足都是任性而为, 恣情恣意。 小说中第三十三回写道: “这日杜少卿大醉了, 竟携着娘子的手, 出了园门, 一手拿着金杯, 大笑着, 在清凉山冈子上走了一里多路, 背后三四个妇女嘻嘻笑笑跟着, 两边看的人目眩神 摇, 不敢仰视。”一个“竟”字仿佛是在说：光天化日，竟如此肆无忌惮，成何体统！他这惊 世骇俗的行为在当时确有明显挑战礼教的意味, 他的特立独行是对那个年代行之已久的原则 规范的“玟渎”。在封建社会里, 男女地位不平等, 男子可以三妻四妾, 女子必须三从四德, 女子是男子的附属品, 像这种夫妻携手游玩是被视为异端, 是不合礼俗的。但是杜少卿却完 全萵视世俗的非议, 任情任性。他愿意亲近下层百姓, 也是因为他们纯朴自然, 不像儒林中 所谓的君子一样忸怩作态, 道貌岸然。

尊重女性, 独树一帜。对妇女持比较开明的态度, 是杜少卿在魏晋名士风范的基础上, 融入时代精神的表现, 体现了一定的民主思想。在《儒林外史》中, 王玉辉的三女儿守节殉 夫, 正是为“节”做出的牺牲, 这也是鲁迅先生所说的“吃人”[6]的礼教。然而, 杜少卿在这样礼 教“吃人”的封建社会里, 独树一帜, 尊重女性, 反对对妇女的歧视和摧残, 是极为难得的。 他笃信夫妻情深, 对妻子体贴入微, 妻子初到南京, 他就陪她四处游山玩水。他拒绝出仕, 固然是因为他不愿做官而拒绝进京, 但是另一面也可以看出他为妻子设想周到, 体贴入微。 此外从他后来对待沈琼枝的态度上与可以看出他是真的按照自己的这种想法来实践, 是用尊 重的态度平等地对待被世人误视为“倚门之娼”或疑为“江湖之盗”的沈琼枝, 赞赏她才华横溢, 钦佩她荗视豪贵。

本应是科举世家守望者的杜少卿, 用他对功名利禄的否定和对底层百姓的肯定, 来反祄现实 社会中为求功名富贵变得麻木不仁的儒林百态, 而被视为科举世家的叛逆者。他崇尚魏晋风 度, 践行着魏晋名士的风范, 不受世俗观念的浸染, 崇尚真性情。他尊重女性, 颇具平等思 想，体现了一定的时代民主精神。

\section{3 杜少卿：儒家思想的守望者}

虽然杜少卿超凡脱俗、遗世独立、萵视权威、狂狷不羁, 从表面上看, 好像是脱离了儒家思 想的束缚。但是从小就受传统儒家思想的教育, 先辈对科举的热衷追求, 父亲对经史、特别 是对《诗经》的备加推崇, 都对杜少卿产生了潜移默化的影响, 他的骨子里还是有传统儒家 思想的基因。他始终没有、也不可能打破儒家思想的藩篱。

遵从孝道一浓烈的宗族情感。杜少卿出生封建地主家庭, 有着显赫的家世背景, 宗族 意识浓烈, 特别强调孝悌, 遵从孝道。“但凡说是见过他家太老爷的, 就是一条狗也是敬重的。” 戏班出身的鲍廷䟩来见他，他因家里有客，本不打算见，但一听说是“先太老爷抬举过的”, 就马上接见, 并且亲自扶住向他行吒头礼的鲍廷胥。他虽然傲视权贵, 不愿和他们交往, 但 是李大人举荐他时, 他因其是先祖的门生, 不能弗其厚意, 置之不理, 所以一反常态, 即刻 动身去答谢。可见杜少卿还是立足于儒家的“孝”。

祭祀泰伯一一殷切的救世之心。泰伯被儒家奉为古今第一贤人，泰伯的“让德”更是被儒 家奉为君子风范的标准。真儒们修建泰伯祠, 很明显是想通过弘扬泰伯的“让德”, 来洗涤当 时争名争利、污浊不堪的社会风气，改善政教，挽救颓世，其目的还是为封建统治者服务。 
杜少卿也积极参与到盛大的泰伯祠祭祀中, 表明他还是没有超出儒家思想的范畴, 还是怀揣 着忧国忧民之心，想要力挽颓世。

杜少卿虽然表面上遗世独立, 酒脱风流, 但内心悲愤苦闷, 他的理想追求并不为世俗庸众所 理解, 还被骂为“专好扯谎骗钱”、“最没有品行”的人。在污浊的现实中，他只能陷入苦闷和 孤独之中, 表现出深深的无可奈何。

\section{3. 吴敬梓思想倾向解读}

小说中杜少卿的性格之所以如此丰富复杂，是因为现实中吴敬梓的思想结构是复杂的， 所以在塑造 杜少卿形象时, 必然打上吴敬梓自己的思想烙印。同样的, 从杜少卿的形象塑造 中, 必然可以看出吴敬梓的思想倾向, 从而探析当时社会的思潮。从杜少卿的身上, 不难看 出, 吴敬梓的思想至少有三个重要组成部分: 正统的儒家思想、魏晋六朝风尚以及明清之际 的先进思潮。

\section{1 正统儒家思想的支配}

杜少卿所处的朝代，是一个政治黑暗的时代，吴敬梓所处的“康乾盛世”，也蕴藏着巨大 的社会危机。也就是说, 小说中的背景和现实中的社会都是“无道”。然而在小说中和现实中 都有一大批所谓的儒士, 为功名富贵蝇营狗苟, 完全不顾礼义廉耻。不管是杜少卿还是吴敬 梓, 都对这些假儒阮士厌恶至极, 对这样得来的功名富贵虽之以鼻, 这种态度和行为才是真 正的儒士风范。吴敬梓在《儒林外史》中强调文行出处, 否定功名富贵, 把孝悌和功名富贵 对立起来，正是孔孟“出处”思想在那个时代的具体表现，同时也隐含着作者的政治态度一 对盛世的否定，他看到了盛世背后潜藏的危机。

《儒林外史》之所以把泰伯祠祭祀作为一大盛事, 并且作为小说发展的高潮, 也是与吴 敬梓思想中的儒家基因密切相关。在儒家的思想体系里, “礼”与“德”不可分割, 朱喜总是“德 礼”联用, 强调“德礼则所以出治之本, 而德又礼之本也”[7]。“礼治”是就社会制度而言, “德治” 是就伦理关系而言。儒家是把政治伦理化, 伦理政治化 ${ }^{1}$ 。按照礼的精神, 对已要主敬, 对人 要主让 ${ }^{[1]}$ 《左传》说: “礼, 让之主也。”桓宽《盐铁论・授时》: “礼义立, 则耕者让于野; 礼义坏，则君子争于朝。”礼义坏，集中表现在“争”，要治“争”，就要提倡与它相对的“让”。 泰伯三让天下，孔子赞赏他的“让德”，把他作为贤人君子的最高典范。明代陈音在《重修至 德庙记》里阐发: “惟天生民有欲, 欲则易争, 争在利与名。利莫大于忧天下, 名莫高于让天 下, 泰伯以天下让而泯其让之名, 此其所以为至德而孔子称之。”[8] 不管是小说中的明朝还是 现实中的清朝, 都有一大群打着儒家的旗帜争名争利、枉顾礼义廉耻的假儒假士, 不管是小 说中的杜少卿还是现实中的吴敬梓, 都企图通过支持泰伯祠祭祀, 提倡泰伯让德, 来洗涤污 浊的世风, 挽救颓世。

因此, 可以说, 吴敬梓反对的不是功名富贵本身。他痛恨的是现实社会中为求功名富贵, 人可以成痴成狂、可以陏落成鬼的现象。而正是这种争名争利的社会怪相, 让吴敬梓转而从 孔孟的礼治和德治中寻求救世良方。

\section{2 魏晋六朝风尚的熏染}

从杜少卿的性格分析中, 可以看出吴敬梓深受魏晋六朝风尚的熏染, 有浓厚的六朝情结。 吴敬梓在《移家赋》中这样描述南京: “金陵佳丽, 黄旗紫气, 虎踞龙盘, 川流山峙, 桂桨兰 舟, 药栏花砌, 歌吹沸天, 绮罗扑地, 实历代之帝都, 多昔人之旅寄。爱买数椽而居, 遂有 终焉之志。”[1] 他之所以移家南京, 是和追慕六朝文采风流分不开的。他这样描述在南京的 心情: “常打虫而自如, 乃送鸿而高视; 吊六代之英才, 忽怆焉而陨涕! ”[1] 可见, 作为六朝

\footnotetext{
1 Ames R T. Recovering a confucian conception of human nature: a challenge to the ideology of individualism[J]. Acta Koreana, 2017, 20(1):9-27.
} 
古都的南京对吴敬梓有巨大的吸引力，这里人杰地灵，是明清两代知识分子的摇篮，同时也 唤起吴敬梓对魏晋风度的无限遐想。《儒林外史》中说南京“菜佣酒保都有六朝烟水气”。不管 是小说里的杜少卿还是现实中的吴敬梓, 都与南京有不解之缘。吴敬梓也不惜笔墨, 描绘南 京这座“不夜城”的繁荣景象和风土人情。

魏晋名士虽然表现出纵心肆志, 恣情任性的特征, 然而这种酒脱风流背后却充满着愤世 疥俗的情怀。名士们虽然用自然来对抗名教, 但是未能完全冲破名教的束缚。他们之所以狂 傲不羁, 是因为对现实强烈不满, 他们之所以愤世嫲俗, 是因为救世不成。这使得魏晋风度 具有深刻的一面, 也是后代知识分子崇尚魏晋风度的重要原因。不管是杜少卿还是吴敬梓, 都是表面上超脱风流, 不问俗务, 但是心怀天下, 希望能挽救颓废的世风, 而这个愿望又不 能实现, 所以常常表现出苦闷和孤独的情绪, 进而到自然山水中寻求解脱。因此, 和那些沽 名钓誉、虚伪无聊的假名士不一样, 杜少卿和吴敬梓的思想因这一层救世不成的愤激和苦闷 而显得更加深遂和富有内涵。

\section{3 明清之际先进思潮的影响}

对程朱理学和八股取士的批判。在《儒林外史》中, 杜少卿极力批判八股取士，公开否 定朱喜解经的独尊地位, 著书立说, 抗击理学。他蓝视科举, 断绝了入仕的道路; 他鄙视蝇 营狗苟之徒, 嘲笑钻营功名的藏苶斋: “你这匪类, 下流无耻极矣！”很明显, 吴敬梓是借助 杜少卿之口表达自己对程朱理学和八股举业的否定。而且吴敬梓是把科举制度和程朱理学结 合起来批判的。小说中通过马纯上对各个朝代不同“举业”的“研究”, 点出了当时的科举制度 和程朱理学是相互联系、相互依存, 互为表里的。儒生们越是热衷八股, 就表明受程朱理学 毒害越深，吴敬梓的批判就越深刻。

明清统治者以八股和理学互为表里, 作为加强文化专制和思想统治的工具, 颜李学派旗 帜鲜明地批判他们 ${ }^{[2]}$, 态度坚决。吴敬梓深受颜李思想影响, 在《儒林外史》中极力抨击理 学和八股, 认为它们是败坏社会风气的根源。除了通过对儒林丑态的正面刻画, 如沉迷八股 成狂的范进、道貌岸然的杜慎卿、丧尽天良的严贡生等之外, 还通过描写杜少卿鄙弃功名, 唾弃八股, 从侧面否定科举。此外, 吴敬梓在《儒林外史》中还深刻揭露八股罪恶无处不在, 揭示科举不仅戕害知识分子, 而且遍布下层百姓的生活, 甚至蔓延到闺房。可见八股邪风毒 害之深广，这是一代文人的悲剧，也是一个时代的悲剧。

对金钱势力和市侩主义的否定。吴敬梓在《儒林外史》中对盐商, 以及巴结盐商的人极 其鄙视和痛恨。五河县方家“典当行盐”, 世家余、虞两家便有不知廉耻的人, 不顾祖宗脸面, 与方家结亲。“方家老太太入祠”, 余、虞两家的举人、进士、贡生、监生、秀才等一百多人, 都恭敬地紧随其后。没落的世家子弟纷纷跑去巴结盐商, 正是宗族意识和观念日益淡薄、宗 族走向没落的象征。吴敬梓认为宗族的衰落是社会腐化的主要原因之一, 而金钱势力和市侩 主义的猖獗是宗族衰落的重要原因。吴敬梓从门阀世族的优越感和自尊自豪出发, 对那些全 身充斥铜臭味的盐商, 以及忘记自己高贵的门第而向盐商献媚的世家隍落子弟予以尖刻的嘲 讽。作为现实主义大师的吴敬梓敏感地意识到金钱势力对宗法家庭的腐蚀和瓦解, 所以他在 《儒林外史》中企图通过孝悌来维护宗法制, 挽救颓废的世风。

\section{4. 结论}

《儒林外史》刻画了封建末世知识分子的精神状态，探讨一代文人的命运出路，是对封 建社会文人心态的一个总结, 是一部浓缩的士史。生活在封建社会回光返照时期的吴敬梓, 深深地感受到了无路可走的悲哀, 表现出了现实主义艺术大师对时代本质和趋势的可贵的敏 感认识。吴敬梓把八股科举、程朱理学和全社会积重难返、无可救药的腐败现象联系在一起

\footnotetext{
2 Elman B A. Late Traditional Chinese Civilization in Motion, 1400-1900[M]// Motion and Knowledge in the Changing Early Modern World. Springer Netherlands, 2014:169-188.
} 
进行批判, 通过塑造一组组人物形象及其之间的对比，讽刺了在科举和时文的茶毒下造成人 格扭曲和道德败坏的市侩无赖、婳儒假士, 襄扬了一批在颓败的衰世中依然能保持社会良心 和独立人格的贤人名士、市井奇人，并在他们身上寄托了美好的愿望。他想用原始儒学来修 正、完善士子的人格，觉得讲求礼乐仁政和君子式的“文行出处”才是挽救世风的途径，但又 清醒地认识到这是不现实的。《儒林外史》的深刻之处在于，它批判的不是一个人，而是一个 制度，它探讨的不是一个人的命运，而是一个群体的出路问题，它编织了一个“礼乐兵农”的 理想花环，但又亲手打碎它。吴敬梓思想的矛盾也正是其深刻之处。然而，吴敬梓并没有认 识到社会腐败的根源, 没有真正突破儒家思想的束缚, 这不是吴敬梓的错, 而是时代的局限。

\section{References}

[1] Li Hanqiu. Research materials of the scholars. [M]. Shanghai: Shanghai ancient book publishing house. 1984: 129, 99, 10, 34, 12, 25.

[2] Wu Jingzi. Lin Lin Wai Shi [M]. Beijing: People's Literature Publishing House. 1977: 353. The text of this book is written in the book.

[3] Gu Yanwu, RI Zhi Lu, [M]., Chinese culture collation Society. 1936: 306.

[4] Lu Xun. Changes in the history of Chinese novels [M]. Beijing: Chinese literature and history Publishing House. 2001: 325.

[5] Lu Xun Lu Xun talks about Chinese culture [M]. Changchun: Jilin people's publishing house. 2009: 89.

[6] Zhou Zuoren Lu Xun's character [M]. Shijiazhuang: Hebei Education Press. 2002: 17.

[7] Zhu Xi. Henan Cheng's suicide note [M]. Shanghai: commercial printing press.1935: 328.

[8] Zhu Xi, four books and chapters, notes, [M]. Beijing: Zhonghua Book Company. 1983: 54.

[9] Ames R T. Recovering a confucian conception of human nature: a challenge to the ideology of individualism[J]. Acta Koreana, 2017, 20(1):9-27

[10] Elman B A. Late Traditional Chinese Civilization in Motion, 1400-1900[M]// Motion and Knowledge in the Changing Early Modern World. Springer Netherlands, 201 